\title{
Treatment of hypercalcaemia in thyrotoxicosis with aminohydroxypropylidene diphosphonate
}

\author{
T.T. Tan ${ }^{1}$, A.A. Alzaid ${ }^{1}$, N. Sutcliffe ${ }^{1}$, M.D. Gardner, ${ }^{2}$ J.A. Thomson ${ }^{1}$ and I.T. \\ Boyle ${ }^{1}$
}

University Departments of ${ }^{1}$ Medicine and ${ }^{2}$ Biochemistry, Royal Infirmary, Glasgow G31 2ER, UK.

\begin{abstract}
Summary: Two patients had symptomatic hypercalcaemia accompanying thyrotoxicosis, despite initial treatment with volume repletion, beta blockade and antithyroid drugs. They were further managed with intravenous infusions of aminohydroxypropylidene diphosphonate resulting in rapid normalization of the serum calcium, with relief of symptoms. Aminohydroxypropylidene diphosphonate effectively suppressed the increased bone resorption of thyrotoxicosis without any undesirable adverse effects.
\end{abstract}

\section{Introduction}

The tendency towards hypercalcaemia in thyrotoxicosis has been documented. ${ }^{1}$ Reported incidence of hypercalcaemia in thyrotoxicosis is between $8-22 \% .^{2,3}$ Usually the hypercalcaemia is mild but occasionally it is severe enough to be symptomatic or even life-threatening, and urgent treatment specifically directed to the hypercalcaemia is therefore occasionally desirable.

Previous studies,4-6 have shown the hypercalcaemia of thyrotoxicosis to be due primarily to increased bone resorption, although relative immobilization during hospitalization may sometimes play a contributory role. ${ }^{3}$ Intravenous infusion of aminohydroxypropylidene diphosphonate (APD) has been shown by ourselves and others ${ }^{7-10}$ to be effective and safe in treating malignancy-induced hypercalcaemia by inhibiting bone resorption. The efficacy of intravenous infusion of APD in the treatment of hypercalcaemia of thyrotoxicosis was evaluated in the following two patients.

\section{Case reports}

\section{Case 1}

A 28 year old woman with mild chronic renal failure resulting from a neurogenic bladder due to spinal bifida and recurrent urinary tract infection

Correspondence: T.T. Tan, M.R.C.P.

Accepted: 3 September 1987 was admitted with a 3 month history of progressive weight loss, anorexia, intractable vomiting, dehydration, wasting, sinus tachycardia and a small goitre. Initial and subsequent biochemistry (Table I) confirmed the diagnosis of thyrotoxicosis complicated by hypercalcaemia. Thyroid hormones and thyroid stimulating hormone (TSH) were measured by radio-immunoassay. Plasma parathyroid hormone (PTH) was measured using a double-antibody (Wellcome AS 211/23) radioimmunoassay which recognizes both $\mathrm{N}$ and $\mathrm{C}$ terminal ends of the hormone molecule, whilst the other biochemical values in Table I were measured as previously described, ${ }^{8,11,12}$ with serum calcium levels being corrected to a serum albumin of $47 \mathrm{~g} / \mathrm{l}$.

Despite one week of treatment with intravenous saline rehydration and oral carbimazole $45 \mathrm{mg} / \mathrm{day}$, she remained symptomatic and hypercalcaemic at $3.35 \mathrm{mmol} / \mathrm{l}$. Two infusions of APD $5 \mathrm{mg}$ each in $250 \mathrm{ml}$ normal saline over 4 hours were then given at 4 day intervals, with restoration of serum calcium and true fasting urinary calcium:creatinine to normal 5 days after the first infusion (Figure 1), in addition to symptomatic improvement. There were no untoward side effects and she has remained normocalcaemic since.

\section{Case 2}

A 43 year old man presented with typical symptoms and signs of thyrotoxicosis. In addition, he had prominent complaints of polyuria, polydipsia, nausea and vomiting of one month's duration. The clinical diagnosis of thyrotoxicosis-induced hyper-

(C)The Fellowship of Postgraduate Medicine, 1988 
Table I Biochemical findings in the two patients with thyrotoxic hypercalcaemia at diagnosis

\begin{tabular}{lccc}
\hline & Case 1 & Case 2 & Normal range \\
\hline Adjusted calcium $(\mathrm{mmol} / \mathrm{l})$ & 3.20 & 3.20 & $2.2-2.6$ \\
Phosphate $(\mathrm{mmol} / \mathrm{l})$ & 1.90 & 1.70 & $0.7-1.4$ \\
Alkaline phosphatase $(\mathrm{U} / \mathrm{l})$ & $455^{*}$ & 230 & $80-280$ \\
Albumin $(\mathrm{g} / \mathrm{l})$ & 29 & 37 & $35-55$ \\
Urea $(\mathrm{mmol} / \mathrm{l})$ & 28.1 & 8.5 & $2.5-8.0$ \\
Creatinine $(\mu \mathrm{mol} / \mathrm{l})$ & 250 & 80 & $40-130$ \\
Ca:Cr $\dagger(\mathrm{mmol}: \mathrm{mmol})$ & 1.79 & 2.42 & $0.03-0.70$ \\
OHP:Cr $(\mathrm{mmol}: \mathrm{mmol})$ & - & 0.200 & undetectable-0.030 \\
PTH $(\mathrm{ng} / \mathrm{l})$ & 250 & $<200$ & undetectable-600 \\
Thyroxine $(\mathrm{nmol} / \mathrm{l})$ & 249 & 326 & $55-144$ \\
Triiodothyronine $(\mathrm{nmol} / \mathrm{l})$ & 6.7 & 14.6 & $0.9-2.8$ \\
TSH $(\mathrm{mU} / \mathrm{l})$ & $<0.8$ & $<0.8$ & undetectable-5.0 \\
\hline
\end{tabular}

*Isoenzymes indicate hepatic origin; $\nmid \mathrm{Ca}: \mathrm{Cr}=$ urinary calcium:creatinine ratio; $\ddagger 0 \mathrm{HP}: \mathrm{Cr}=$ urinary hydroxyproline: creatinine ratio
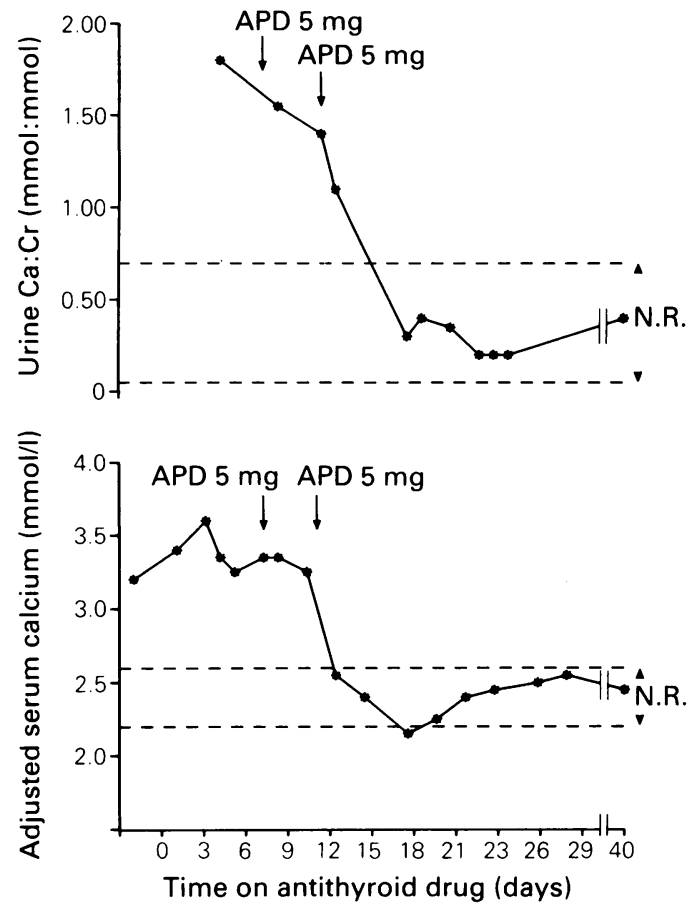

Figure 1 Case 1 - effect of APD on adjusted serum calcium and indices of bone resorption. N.R.-normal range.

calcaemia was made and substantiated biochemically (Table I). Propylthiouracil $400 \mathrm{mg} /$ day, propranolol $120 \mathrm{mg} /$ day and volume repletion with intravenous saline were started. At day 19 of treatment he was still hypercalcaemic with persistence of nausea and polyuria. At this stage a single infusion of $15 \mathrm{mg}$ APD in $500 \mathrm{ml}$ normal saline over 4 hours was administered with rapid fall of serum calcium (Figure 1) and urinary excretion of calcium and hydroxyproline to normal (Figure 2). Transient pyrexia was the only observed side effect, and has been noted previously by ourselves $^{8}$ and others (O.L.M. Bijvoet, 1978, personal communication). The pyrexia lasts only an hour or two and appears to accompany the initial rapid change in bone resorption although the mechanism is uncertain. Transient pyrexia may also accompany the use of APD in the management of Paget's disease. The normalization of his serum calcium was sustained.

\section{Discussion}

The marked increase in true fasting urinary excretion of calcium and hydroxyproline in both cases (Figures 1 and 2) are consistent with increased bone resorption as reported by earlier studies. ${ }^{14^{-6}}$ In both patients PTH was appropriately suppressed.

Oral propranolol in conventional dosage as used in the second case for control of thyrotoxic symptoms is ineffective by itself in lowering serum calcium. ${ }^{13.14}$ The calcium lowering effect of antithyroid drugs in both cases was slow but sustained. The first and second cases were still hypercalcaemic after 10 and 19 days of treatment respectively (Figures 1 and 2) in accord with a previous report $^{15}$ that normalization of serum calcium concentration might take 2 to 8 weeks of antithyroid therapy. In contrast, infusions of APD rapidly normalized the serum calcium concentration in 1 and 5 days (Figures 2 and 1) in cases 2 and 1 

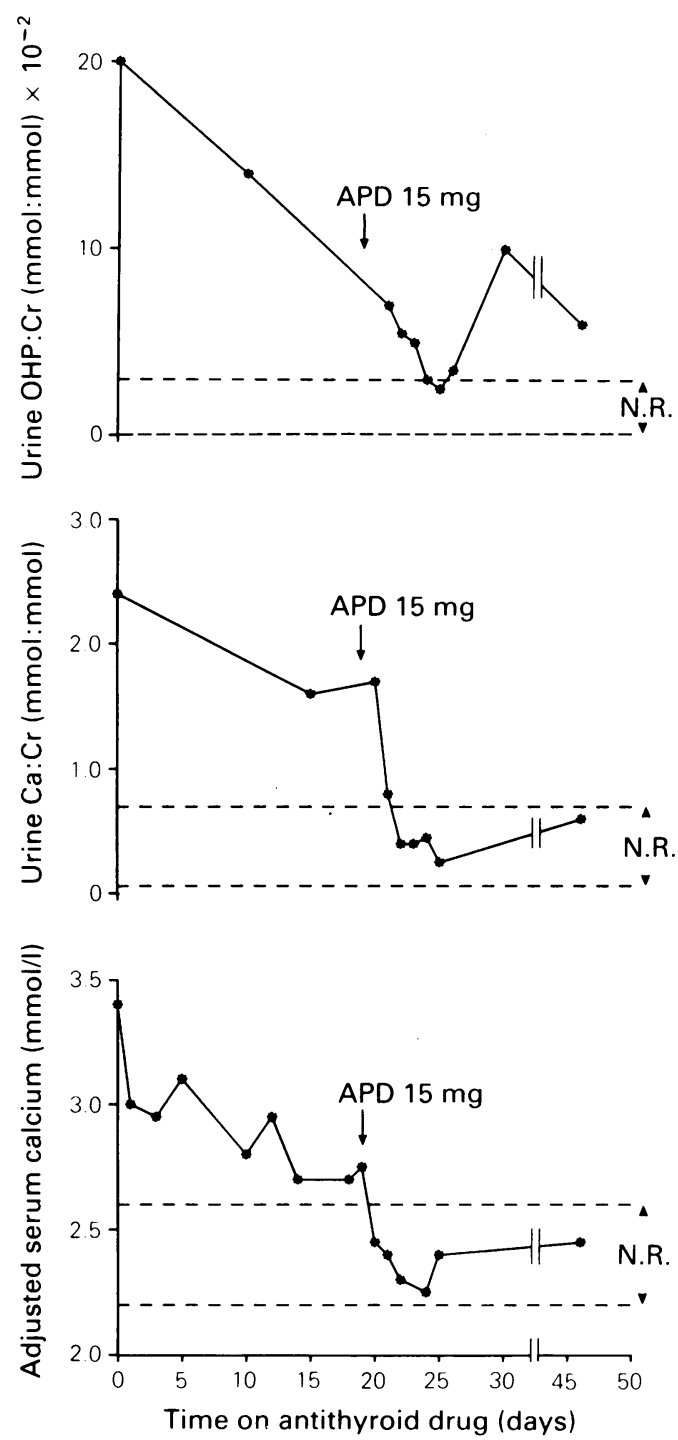

Figure 2 Case 2 - effect of APD on serum calcium and indices of bone resorption. N.R.-normal range.

\section{References}

1. Adams, P.H., Jowsey, J., Kelly, P.S. et al. Effects of hyperthyroidism on bone and mineral metabolism in man. $Q J$ Med 1967, 36: 1-15.

2. Baxter, J.D. \& Bondy, P.K. Hypercalcemia of thyrotoxicosis. Ann Intern Med 1966, 65: 429-442.

3. Rude, R.K., Oldham, S.B., Singer, F.R. \& Nicoloff, J.T. Treatment of thyrotoxic hypercalcemia with propranolol. $N$ Engl J Med 1976, 294: 431-433. respectively by inhibition of bone resorption as indicated by the rapid fall of urinary calcium and hydroxyproline to normal (Figures 1 and 2) with transient pyrexia in case 2 as the only side effect. Relief of symptoms parallelled the falls in serum calcium.

In contrast to intravenous calcitonin ${ }^{16}$ and propranolol, ${ }^{3.13}$ the normalized serum calcium concentration was sustained without further infusion of APD. This could be due both to the more prolonged calcium lowering action of APD, as described up to 8 days in a study ${ }^{10}$ on hypercalcaemia of malignancy, and to the continued use of antithyroid drugs which has a slower but sustained effect.

In both cases vomiting was a prominent feature of the hypercalcaemia and delayed the diagnosis in the first case.

The hypoalbuminaemia and hyperphosphataemia noted in both cases (Table I) are recognized features of thyrotoxicosis. ${ }^{1}$ The alkaline phosphatase seen in case 1 was inappropriately high to be derived from bone and a hepatic origin, as suggested by concomitant elevation of other liver enzymes, was subsequently confirmed by an alkaline phosphatase isoenzyme study. A normocalcaemic relapse 3 months later with similar elevation of liver enzymes suggests association of the two conditions. A causal relationship between jaundice and thyrotoxicosis has previously been reported. ${ }^{16}$

In conclusion, one or two infusions of APD used concomitantly with volume repletion and antithyroid drugs is an effective and safe method of controlling significant and symptomatic hypercalcaemia in thyrotoxicosis.

\section{Acknowledgements}

Aminohydroxypropylidene diphosphonate for intravenous use was supplied by Ciba-Geigy Pharmaceuticals.

We would like to thank Mrs Legrix for secretarial assistance.

4. Krane, S.M., Brownell, G.L., Stanbury, J.B. \& Corrigan, A. The effect of thyroid disease on calcium metabolism in man. $J$ Clin Invest 1956, 35: 874-887.

5. Mundy, G.R., Shapiro, J.L., Bandelin, J.G., Canalis, E.M. \& Raisz, L.G. Direct stimulation of bone resorption by thyroid hormones. J Clin Invest 1976, 58: 529-534. 
6. Hendriks, J.Th.A.M. \& Smeenk, D. Investigation of bone and mineral metabolism in hyperthyroidism before and after treatment using calcitonin, ${ }^{47} \mathrm{Ca}$ and balance studies. Acta Endocrinol 1979, 91: 77-88.

7. Sleebom, H.P., Bijvoet, O.L.M., von Oosterous, A.T., Gleed, J.H. \& O'Riordan, J.L.H. Comparison of intravenous (3-amino-1-hydroxypropylidene)-1, 1biphosphonate and volume repletion in tumourinduced hypercalcaemia. Lancet 1983, i: 239-243.

8. Ralston, S.H., Gardner, M.D., Dryburgh, F.J., Jenkins, A.S., Cowan, R.A. \& Boyle, I.T. Comparison of aminohydroxypropylidene diphosphonate, mithramycin and corticosteroid/calcitonin in treatment of cancer-associated hypercalcaemia. Lancet 1985, ii: 907-910.

9. Ralston, S.H., Alzaid, A.A., Gardner, M.D. \& Boyle, I.T. Treatment of cancer associated hypercalcaemia with combined aminohydroxypropylidene diphosphonate and calcitonin. $\mathrm{Br} \mathrm{Med} J$ 1986, 292: 1549-1550.

10. Cantwell, B.M. \& Harris, A.L. Effect of single high dose infusions of aminopropylidene diphosphonate on hypercalcaemia caused by cancer. $\mathrm{Br} M e d J$ 1987, 294: 467-469.

11. Ralston, S.H., Fogelman, I., Gardner, M.D. \& Boyle, I.T. Relative contribution of humoral and metastatic factors to pathogenesis of hypercalcaemia in malignancy. Br Med J 1984, 288: 1405-1408.

12. Gardner, M.D., Dryburgh, F.J., Fyffe, J.A. \& Jenkins, A.S. Predictive value of derived calcium figures based on the measurement of ionised calcium. Ann Clin Biochem 1981, 18: 106-109.

13. Feeley, J. Propranolol and the hypercalcaemia of thyrotoxicosis. Acta Endocrinol 1981, 98: 528-532.

14. Jones, M.K. \& Papoulos, S.E. Control of hypercalcaemia in thyrotoxicosis. Postgrad Med J 1979, 55: 891-893.

15. Twycross, R.G. \& Marks, V. Symptomatic hypercalcaemia in thyrotoxicosis. Br Med J 1970, 2: 701-703.

16. Buckle, R.M., Mason, A.M.S. \& Middleton, J.E. Thyrotoxic hypercalcaemia treated with porcine calcitonin. Lancet 1969, i: 1128-1130. 